\title{
The Effect of Dental Paste with Herbal Content on Remineralization and the Imaging with Fluorescent Technique in Teeth with White Spot Lesion
}

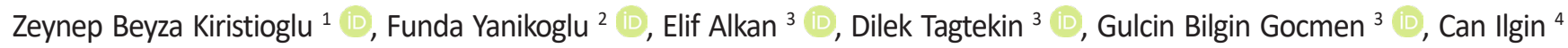 \\ ${ }^{1}$ Department of Oral and Maxillofacial Surgery, Faculty of Dentistry, Marmara University, Istanbul, Turkey. \\ ${ }^{2}$ Department of Restorative Dentistry, Faculty of Dentistry, Istanbul Kent University, Istanbul, Turkey. \\ ${ }^{3}$ Department of Restorative Dentistry, Faculty of Dentistry, Marmara University, Istanbul, Turkey. \\ ${ }^{4}$ Department of Public Health, Faculty of Medicine, Marmara University, Istanbul, Turkey. \\ Correspondence Author: Elif Alkan \\ E-mail: elifalkan111@gmail.com
}

Received: 20.12.2020 Accepted: 04.04.2021

\begin{abstract}
Objective: To evaluate the effect of Gumgumix herbal toothpaste on remineralization of white spot lesions with a laser fluorescent system called FluoreCam. It is a pilot study.

Methods: The FluoreCam system was used for the fluorescence imaging of the fifteen teeth with white spot lesions. During the study, the patients continued to use the previously owned toothpastes, addition to Gumgumix. Gumgumix was applied on the lesion area with a finger pressure twice a day and was not rinsed mouth after, only a limited spit and was prevented from taking any fluid during 30 minutes. The "Compare" option in the FluoreCam system was used to differentiate the situation before and after the use of the paste; if the marked area were yellow "No Change"; blue "Sound Surface"; green "Improving"; light blue "Mild Improving" and red meant "Worsening".

Results: Of the 13 lesions that were "Suspect Surface" initially, 46\% were identified as "Mild Improving", $7 \%$ as "Moderate Worsening", 30\% as "No Change", and 15\% as "Sound Surface". Two of the white spot lesions were recovered totally as $100 \%$.

Conclusion: After use of Gumgumix for one week, remineralization was observed on teeth with white spot lesion. The white spot lesions on two teeth were totally healed.

Keywords: Remineralization, Herbal toothpaste, White spot lesion, Laser fluorescence.
\end{abstract}

\section{INTRODUCTION}

Tooth decay is one of the most common chronic diseases in the world and it may cause tooth loss when appropriate treatment is not applied. The modern dentistry concept aims to improve the aesthetic and function of the tooth through the process of remineralization by preventing the progression of caries. Thus, non-invasive treatment of caries lesions without cavity preparation have been developed (1). Demineralization occurs by the dissociation of mineral ions in the dental hard tissues from the hydroxyapatite crystals. Precipitation of hydroxyapatite crystals is called remineralization. Both processes take place on the tooth surface and a large number of hydroxyapatite crystals may be lost before deteriorating tooth integrity. However, gaps are formed on the tooth surface as a result of disintegration of the hydroxyapatite structure. Moreover, demineralization is a reversible process; therefore, partially demineralized hydroxyapatite crystals in the teeth may return to their original size if the conditions for remineralization is provided (2).
Initial enamel caries is the first stage of dental caries and it is possible to control the caries at this stage. It may be treated with a proper regulation of diet, plaque control and application of appropriate antibacterial agents and thus the demineralized enamel may be remineralized (3). Initial caries lesions are limited to enamel and also called "white spot lesions". Caries on the smooth enamel surface is first seen as white spot lesions. These white spot lesions can only be seen when the tooth surface is dried. These opaque surfaces are chalky white and this color is caused by the loss of transparency due to the expansion of the porosity of the sub-surface area as a result of demineralization (4). Remineralization of initial caries lesions without cavitation; easy to apply, short-term, economical, acceptable by the patient, and it is a very convenient conservative method. Many materials are used to prevent demineralization and to remineralize the tooth surface. These are fluoride-containing gels, vernics, mouthwashes, dental floss and toothpastes (5). 
Besides them, some studies showed positive and promising results of remineralization by using herbal tooth creams $(6,7)$.

Ginger is one of these herbal extracts with antibacterial properties. In ginger, there are many active ingredients including terpene and oleoresin called ginger oil (8). Ginger consists of about $1 \%$ to $3 \%$ of essential oils and non-volatile oleoresin. The main components identified as terpenes are sesquiterpene hydrocarbon and phenolic compounds, gingerol, shogaol and lipophilic rhizome extracts. Potentially active gingerols can be converted to shogaol, zingerone, and paradol $(9,10)$. Ginger and its components show antioxidant activity and prevent damage to macromolecules from free radical and oxidative stress. Ginger also shows antimicrobial activity through gingerol, paradol, shogaol and zingeron (11). Ginger essential oil and oleoresin have shown important antioxidant and antimicrobial activities (12). Gingerol and shogaol have been identified as the most active agents (13). With such properties of ginger, Bilgin et al (14) discovered the remineralization effects of ginger and honey mixture on initial enamel caries lesion with 50 micron depth. Afterwards Korkut et al (15), studied on remineralization effects of this mixture in herbal toothpaste form (Gumgumix, Beka llac, Sultanbeyli, İstanbul, Turkey), reporting the lesions were remineralized quite well compared to the control toothpastes with 1450 ppm fluoride ingredient.

Apart from the remineralization agent it is important to determine the lesions at the early stage and follow the change of the lesion in order to treat demineralization. Thus, it may be evaluated the effectiveness of remineralizing agent applied on the lesion. Traditional caries detection methods are insufficient for the diagnosis and follow-up of the initial caries lesions. For many years explorer has been used for the detection of caries (16). However using explorer may cause defects in the demineralized areas and the cariogenic microflora can be transferred to deeper regions of tooth $(17,18)$. With evolution of technology, non-invasive caries detection methods have been developed (19). Nowadays caries detection methods are able to measure the detected lesions quantitatively and evaluate as numerical data. Numerical evaluation of lesions parameters such as lesion area, lesion depth and mineral loss provides an objective examination (20).

One of the methods used in the diagnosis of initial enamel caries in modern dentistry is laser fluorescence technique (21). The device called FluoreCam, the mineral loss of the tooth can be expressed quantitatively. The FluoreCam system (Therametric, Daraza, Indianapolis, USA) uses the Fluorescence Enamel Imaging (FEI) approach to determine de-or remineralization areas of enamel. The measurements are automatically done by FluoreCam software. This method is simple, fast, repeatable, and able to measure initial caries lesions which may be difficult to diagnose clinically and radiographically. Using FluoreCam as a detection method for mineral changes that have occurred on enamel surface after treatments may increase the patient's confidence to the dentist because it is a painless and non-invasive method (22).
The aim of this pilot study was to clinically visualize any remineralization on the teeth with a white spot lesion by a laser fluorescence system, FluoreCam using the herbal toothpaste, Gumgumix.

\section{METHODS}

\subsection{Study Subjects}

A total of 15 teeth with a white lesion from 6 patients with an age range of 14-25 applied to the clinics of Marmara University, Faculty of Dentistry were included in the study from May 2019 to June 2019. Patients allergic to any herbal toothpaste were excluded. Patients with DMFT index 3 or less and with no gingivitis or periodontitis were included.

All patients were informed about the study and a voluntary consent form was signed. All procedures were conducted according to the Declaration of Helsinki. Ethical approval was obtained from the Marmara University, Faculty of Dentistry Clinical Researches Ethics Committee (Reference number: 2019-304).

\subsection{Clinical Examination}

A standard 'Patient Tracking Form' has been prepared for each patient. In this form, the patient's nutritional details, the frequency of toothpaste and brush usage, the current toothpaste and toothbrush used, how many times he rinsed his mouth after brushing, the use of orthodontic apparatus and the daily meal amount were recorded and the patient's oral examination was performed and air-water spray and eye examination were recorded. The white spot lesions detected were also recorded on the form. Besides, the intraoral view of the white spot lesion was recorded with a mobile phone camera (iPhone 6S).

Five patients with 13 white spot lesions continued using routine toothpaste besides they applied herbal toothpaste Gumgumix (Beka Drug, Sultanbeyli, Istanbul, Turkey) to the lesioned areas twice a day with a finger pressure following tooth brushing for a week as it was a usual application at the in vitro studies. Following use of Gumgumix, they did not rinse their mouth; they only spat and were prevented from taking liquids within 30 minutes. One patient with two white spot lesions kept as control and continued to her routine toothpaste with $1450 \mathrm{ppm} \mathrm{NaF}$, no additional use of Gumgumix toothpaste.

The clinical visualization of remineralization on the teeth with a white spot lesion was carried out by a laser fluorescence system, FluoreCam at baseline and after 1 week from all teeth. The patient's name-surname, age and teeth numbers with white spot lesions were entered into the FluoreCam system. Fluorescence images of the white spot lesioned teeth were obtained with the FluoreCam intraoral camera after drying with air-water spray. Particular attention was paid not to shine the tooth surface while taking the image. 
Fluorescence differences within the lesion in the acquired image were confirmed by the parts indicated by the device and field records were made. This area is in a color that FluoreCam automatically determines. If the area is illustrated by blue color, it shows the healthy surface, and the yellow shows the suspected surface with demineralization. FluoreCam system also ranks the suspicious white lesion from Level 1 to Level 3 according to darkness of the area probably the differences in depthness. Lesion sizes and intensities are evaluated in this study. The number extracted for each image represents the cumulative size for all the red outlines on the screen. Size means the area of the lesion which has lesser mineral content. Intensity means the amount of mineral loss. If the size gets bigger, that means the area of the lesion or the areas where there is less mineral content has increased. Intensity always represented as a negative number. If the negative value gets bigger, that means the lesion (mineral content) has worsened. On the contrary if the value gets smaller, that means the lesion has improved. The "Compare" option in the FluoreCam system was used to differentiate the fluorescence intensity disagreement between baseline and 1 week images. If the marked area is yellow, "No Change"; blue is "Sound Surface"; green is "Improving"; light blue is "Mild Improving"; red is considered as "Worsening". The change in lesion size and density is reported in percent on the "Compare" screen. The statistical analysis of the study was carried out by Stata 15.1 (Stata Corp, College Station, TX) computer programme. In the study, density changegender, size change-gender, density change-carbohydrate consumption, size change-carbohydrate consumption was compared with the Mann-Whitney $U$ test. Moreover, in the change of dimension, "Moderate Worsening" and "No Change" were combined and recorded as "worsened"; "Sound Surface" and "Mild Improving" were combined and recorded as "healthy" and evaluated with Fisher's exact test. Results with a $p$ value below 0.05 were considered significant.

\section{RESULTS}

According to the measurements obtained in the first session, 13 of 15 lesions were determined as "Level 1" and 2 of them as "Level 2". All lesions were "Suspect Surface" and seen in yellow in the first session. One of the control lesions was Level 1 and the other one was Level 2. According to the measurements done in the second session, 11 of the lesions were recorded as "Level 1", two of them as "Level 2" and two of them as "Sound Surface". One of the lesions determined as Level 1 was Level 2 in the first session. Two of the lesions determined as Sound Surface were Level 1 in the first session. In the comparison made at the end of the second session, six of the lesions (46\%), the first session of which was Suspect Surface, were "Mild Improving" and painted in light green color (Figure 1). Four of the lesions (30\%) were shown "No Change" and painted in yellow (Figure 2). Two of them (15\%) were "Sound Surface" and painted in blue, one of them (7\%) were "Moderate Worsening" and painted in pink. According to the percentages seen on the "Compare" screen, eleven of the lesions decreased in size and two of them (15\%) increased in size. While the lesion density decreased in seven of them (53\%), it increased in six. Two of the white spot lesions were $100 \%$ healed. The two control lesions were identified as "No Change". The situation before and after the size was calculated using the Chi-Square test, but since there was only one group in the pre-treatment group, the statistical analysis could not be performed. As a result, out of thirteen lesions initially "Suspect Surface", 46\% were identified as "Mild Improving", 7\% as "Moderate Worsening", 30\% as "No Change", 15\% as "Sound Surface". The comparison of the situation before and after the dimension is shown in Table 1.

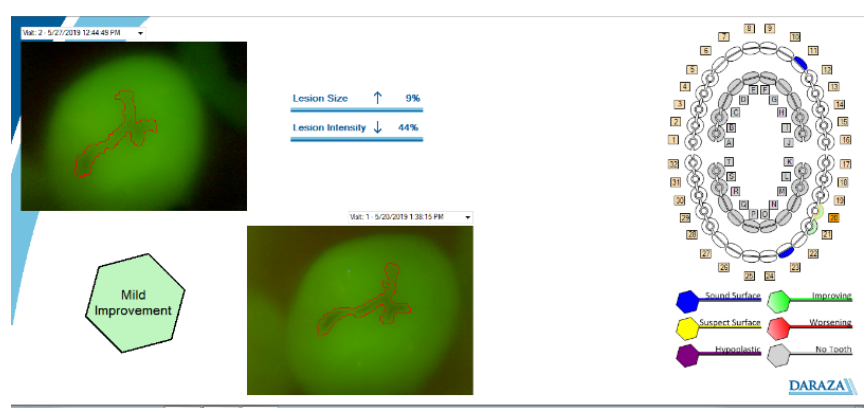

Figure 1. Image of the lesion which showed "mild improving".

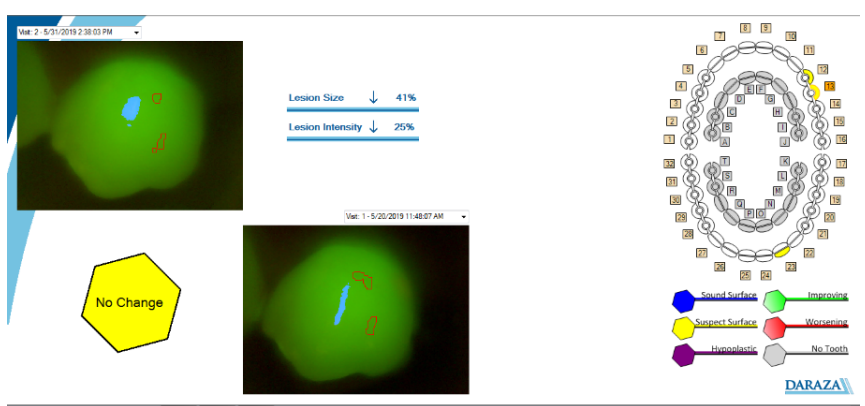

Figure 2. Image of the lesion which showed "no change".

Table 1. Comparison of the before and after of dimensional changes with additionally use of gumgumix toothpaste (difference \%).

\begin{tabular}{|c|c|c|c|c|c|}
\hline $\begin{array}{c}\text { Dimension } \\
\text { (Before) }\end{array}$ & \multicolumn{4}{|c|}{ Dimension (After) } & Total \\
\hline $\begin{array}{c}\text { Suspect } \\
\text { surface } \\
\mathrm{n}(\%)\end{array}$ & $\begin{array}{c}\text { Mild } \\
\text { improving } \\
\mathrm{n}(\%)\end{array}$ & $\begin{array}{c}\text { Moderate } \\
\text { worsening } \\
\mathrm{n}(\%)\end{array}$ & $\begin{array}{c}\text { No change } \\
\mathrm{n}(\%)\end{array}$ & $\begin{array}{c}\text { Sound } \\
\text { surface } \\
\mathrm{n}(\%)\end{array}$ & $\mathrm{n}(\%)$ \\
\hline $13(100)$ & $6(46.15)$ & $1(7.69)$ & $4(30.47)$ & $2(15.38)$ & $\begin{array}{c}13 \\
(100)\end{array}$ \\
\hline
\end{tabular}

Density change-gender, size change-gender, density changecarbohydrate consumption, size change-carbohydrate consumption was compared with the Mann-Whitney $U$ test. $p$ values were $0.1564,0.1069,0.4972,0.9060$ respectively and no statistically significant results were obtained. In the change of dimension, "Moderate Worsening" and "No Change" were combined and recorded as "worsened"; "Sound Surface" and "Mild Improving" were combined 
and recorded as "healthy". Fisher's exact test was used to establish a relationship between change in dimension and carbohydrate consumption $(p=0.196)$ as well as between change in dimension and gender $(p=0.685)$. Due to the small number of patients no statistically significant results were found.

\section{DISCUSSION}

In today's dentistry, the tendency towards natural and biocompatible products has increased to avoid health problems increasing with the development of technology. Hence researchers have been trying to develop dental products containing mostly natural ingredients (23). For this purpose, herbal extracts and their oils have been used in the pharmaceutical, cosmetic, food and beverage industries. There are plenty of studies that show that plants have properties such as antioxidant, anti-inflammatory, antiviral, antibacterial, antidiabetic and anticarcinogen effect (24). However, apart from the listed effects there are limited number of studies showing the effects of the herbal extracts on the cariogenic bacteria and on remineralization. Recently herbal extracts have been used as antimicrobial plaque agents in medicine to prevent tooth decay and reduce gingivitis and have received special attention as they are not chemical and synthetic (25). Since herbal products are natural, they are safer than synthetic products without showing any side effects. Furthermore, they are economic and available locally.

Herbal toothpaste Gumgumix which is recently produced in dentistry, has antibacterial properties and remineralizing effect due to ginger and honey content which has been observed in various studies $(14,15,26)$. Although a remineralization process occurs on enamel tissue, the mechanism of remineralization by this paste is not known. Remineralizing effect of toothpastes may be achieved by the presence of active agents in the mouth during 30-40 minutes. Unfortunately, in daily routine, people rinse with water immediately and the active agent leaves outside of the mouth. In this way, the anti-caries effect is proportionally reduced with each rinsing with water. In this study, we recommended to apply the active ingredient of the test material herbal toothpaste (Gumgumix) with the finger on the tooth surface for one minute to be more effective and afterwards no rinsing with water.

Göçmen et al. compared the effects of $\mathrm{NaF}$, mixture of ginger and honey, mixture of ginger, honey and chocolate, and rosemary oil on the remineralization in vitro and they observed the changes in surface microhardness values statistically significant in all treatments groups and the most significant study group was the mixture of ginger and honey (14). Similar results as demonstrated in Table 1 were obtained in our study.

One of the ingredients in Gumgumix is honey, which is a mixture of sugars mainly fructose and glucose. Recent studies showed that honey is an antiseptic and antibacterial agent as containing hydrogen peroxide $\left(\mathrm{H}_{2} \mathrm{O}_{2}\right)$, methylglyoxal and bee defensin-1 $(27,28)$. Additionally, Patel et al. reported ginger and honey are more effective than gentamycin on S. Mutans (29). As supporting views, Premkishore et al. used ginger with honey against Streptococcus mutants in an in vitro study and reported considerable antibacterial effect against $\mathrm{S}$. mutants in antibiotic sensitivity test (5). In another study, ginger extracts are used to inhibit the S. mutants and it is reported that the experimental group with the ginger extract showed significantly higher reduction of the $\mathrm{S}$. mutants concentration (30). Besides antibacterial properties, ginger has an effect on saliva and apatite stimulation, in this way ginger is a potential natural agent to treat enamel demineralization (31).

In this study the effect of herbal toothpaste, Gumgumix, on remineralization of enamel was evaluated by FluoreCam system. The Fluorecam system does not contain X-ray which is the biggest advantage. On the other side there are some aspects should be careful with when using the FluoreCam. During the process of image taking, there might be some shining areas on the surface, may cause the existing lesions not to be detected. In this case, the image should be repeated. However, FluoreCam have some disadvantages such as the inability on having a differential diagnosis in deep caries with exposed pulp, failure in the diagnosis of secondary caries in the teeth with restoration and adjacent to restoration, and detecting discoloration or plaque on the tooth surface as a fluorescence loss (false positive value).

In present study one of the patients had the initial enamel lesion, which was not visible due to the orthodontic brackets. The patient with the bracket gave a false positive response as if there was a lesion in the presence of plaque. It was observed that there was no lesion after removing the plaque. Also, it gave false positive answers in the restoration area of the teeth with restoration. However, it was able to detect the initial enamel lesions, which were determined or not determined with the naked eye, on clean surfaces at the stages with a white lesion or before the white lesion. Both white spot lesions that healed completely were small lesions located on the upper lateral. Ease of application of the agent on the surface, lack of fissure and small initial lesion size are likely to be effective in healing. It was determined that $46 \%$ of the lesions were "Mild Improving" in the second appointment, they were larger than those which completely healed and some of them had initial fissure caries causing reduction on the recovery rate.

Another point to consider is that the images taken in the first and second appointments should be on the same angulation. If the image is taken from a different angle in the second appointment, the change in lesion size may be reported incomplete. While taking the image, the unit' light should be off and the tooth surface should be dried.

Korkut et al. reported that FluoreCam can detect lesions around the orthodontic brackets and achieved a successful remineralization with ginger-honey mixture and demonstrated that it is possible to measure demineralization around orthodontic brackets and to detect the weekly mineral 
content alterations by using FluoreCam device (15). Similar results have been found in our study. The daily application of the herbal toothpaste Gumgumix containing active ingredient ginger and honey demonstrated inhibitory effect on demineralization and have enhanced remineralization on enamel (Table 1).

In present study only one lesion showed "Moderate Worsening" at the end of the second appointment. According to the information received from that patient, she did not use Gumgumix regularly.

Due to few patients as a pilot study, no statistical results could be obtained. However, the difference between p50 values coincides with the results obtained in the clinical studies $(14,15,26)$. Also, according to the data obtained in comparing the lesion sizes before and after, it was determined that $61 \%$ of the lesions had improvement. We think that our study might yield statistically significant results if the number of patients were higher than the present.

According to the results derived from this study, the daily application of Gumgumix provided enhanced remineralization just in a week. We think that mineral content and antibacterial effect of ginger in Gumgumix may have some role on remineralization process. We also suppose that regular use of Gumgumix may reduce cariogenic microflora which may lead to reduced demineralization. Due to its content, Gumgumix may create an environment which favors for remineralization. Applying Gumgumix on the tooth surfaces helps to repair demineralized areas by preventing further mineral loss and enhancing increased mineral intake.

\section{CONCLUSION}

Under the conditions of this in vivo study, the herbal toothpaste Gumgumix was determined as an effective agent on preventing and also reversing the demineralization. Even though the remineralizing mechanism of Gumgumix has not been known, additional research on this herbal-based toothpaste is required to identify its potential benefits and efficacy for its regular use in the oral hygiene products. FluoreCam caries detection device is found as useful for determining mineral density and lesion size changes occurring in enamel lesion even within a week. With this promising results, herbal toothpaste Gumgumix containing ginger and honey may safely be used in daily routine as preventive agent and treatment of initial enamel caries lesions in oral hygiene.

\section{REFERENCES}

[1] Nagarathana C, Sakunthala BK, Naveena Preethi P. An update on current remineralizing agent. OHDM 2015;14(4):183-187.

[2] Featherstone JD, Chaffee BW. The evidence for caries management by risk assessment (CAMBRA). Adv Dent Res 2018;29(1):9-14.

[3] Guerrieri A, Gaucher C, Bonte E, Lasfargues JJ. Minimal intervention dentistry: part 4. Detection and diagnosis of initial caries lesions. Br Dent J 2012;213(11):551-557.
[4] Arends J, Christoffersen J. The nature of early caries lesions in enamel. J Dent Res 1986;65(1):2-11.

[5] Scheifele E, Studen-Pavlovich D, Markovic N. Practitioner's guide to fluoride. Dent Clin North Am 2002;46(4):831-846.

[6] de Carvalho CCCR, Caramujo MJ. Ancient procedures for the high-tech World: health benefits and antimicrobial compounds from the Mediterranean Empires. Open Biotechnol J 2008;2(1):235-246.

[7] Reynolds EC. Remineralization of enamel subsurface lesions by casein phosphopeptide-stabilized calcium phosphate solutions. J Dent Res 1997;76(9):1587-1595.

[8] Zick SM, Djuric Z, Ruffin MT, Litzinger AJ, Normolle DP, Alrawi $S$, Feng MR, Brenner DE. Pharmacokinetics of 6-gingerol, 8-gingerol, 10-gingerol, and 6-shogaol and conjugate metabolites in healthy human subjects. Cancer Epidemiol Biomarkers Prev 2008;17(8):1930-1936.

[9] Hasan HA, Rasheed Raauf AM, Abd Razik BM, Rasool Hassan BA. Pharmaceut chemical composition and antimicrobial activity of the Crude extracts isolated from Zingiber officinale by different solvents. Pharmaceute Anat Acta 2012;3(9):184.

[10] Govindarajan VS. Ginger - chemistry, technology, and quality evaluation: part 2. Crit Rev Food Sci Nutr 1982;17(3):189-258.

[11] Giriraju A, Yunus GY. Assessment of antimicrobial potential of $10 \%$ ginger extract against Streptococcus mutans, Candida albicans, and Enterococcus faecalis: an in vitro study. Indian J Dent Res 2013;24(4):397-400.

[12] Bellik Y. Total antioxidant activity and antimicrobial potency of the essential oil and oleoresin of Zingiber officinale Roscoe. Asian Pac J Trop Dis 2014;4(1):40-44.

[13] Atai Z, Atapour M, Mohseni M. Inhibitory effect of ginger extract on Candida albicans. Am J Applied Sci 2009;6(6):10671069.

[14] Bilgin G, Yanikoglu F, Tagtekin D. Effectiveness of some herbals on initial enamel caries lesion. Asian Pac J Trop Biomed 2016;6(10):846-850.

[15] Korkut B, Korkut D, Yanikoglu F, Tagtekin D. Clinical assessment of demineralization and remineralization surrounding orthodontic brackets with FluoreCam. Asian Pac J Trop Biomed 2017;7(4):373-377.

[16] Tranaeus S, Shi XQ, Angmar-Mansson B. Caries risk assessment: methods available to clinicians for caries detection. Community Dent Oral Epidemiol 2005;33(4):265-273.

[17] Lussi A. Validity of diagnostic and treatment decisions of fissure caries. Caries Res 1991;25(4):296-303.

[18] Lobo MM, Pecharki GD, Gushi LL, Dias Silva D, Cypriano S, Meneghim MC, Pereira AC. Occlusal caries diagnosis and treatment. Braz J Oral Sci 2003;2(6):239-244.

[19] Loesche WJ, Svanberg ML, Pape HR. Intraoral transmission of Streptococcus mutans by a dental explorer. J Dent Res 1979;58(8):1765-1770.

[20] Abufarwa M, Noureldin A, Azimaie T, Campbell PM, Buschang $\mathrm{PH}$. Preventive effects of carbondioxide laser and casein phosphopeptide amorphous calciumphosphate fluoride varnish on enamel demineralization: A comparative, in vitro study. J Invest Clin Dent 2019;10(2):e12400.

[21] Sudjalim TR, Woods MG, Manton DJ, Reynolds EC. Prevention of demineralization around orthodontic brackets in vitro. Am J Orthod Dentofacial Orthop 2007;131(6):705.

[22] Durmus B, Durhan A, Gokkaya B, Kitiki B, Yanikoglu F, Kargul B. A novel quantitative light-induced fluorescence device for 
monitoring molar-incisor hypomineralization. Niger J Clin Pract 2017;20(1):52-57.

[23] Premkishore K, Umapathy T, Kathariya MD, Agrawal A, Kumar PP, Kallampilly G. Effect of honey and aqueous ginger extract against Streptococcus mutans isolated from extracted carious deciduous teeth. J Indian Acad Oral Med Radiol 2013;25(4):265-267.

[24] Nogueira de Melo GA, Grespan R, Fonseca JP, Farinha TO, Silva EL, Romero AL, Bersani-Almado CA, Nakamura Cuman RK. Inhibitory effects of ginger (Zingiber officinale Roscoe) essential oil on leukocyte migration in vivo and in vitro. J Nat Med 2011;65(1):241-246.

[25] Poureslami H. The effects of plant extracts on dental plaque and caries. Li M, editor. Contemporary Approach to Dental Caries. Croatia: IntechOpen; 2012.p.395-403.

[26] Bilgin G, Yanikoglu F, Tağtekin D. Remineralization potential of herbal mixtures: An in situ study. Pripex-Inx J Res 2016;5(2):264-268.

[27] Kwakman PH, Zaat SA. Antibacterial components of honey. IUBMB Life 2012;64(1):48-55.
[28] Rehman R, Akram M, Akhtar N, Jabeen Q, Saeed T, Shah SMA, Ahmed K, Shaheen G, Asif HM. Zingiber officinale Roscoe (pharmacological activity). J Med Plants Res 2011;5(3):344348.

[29] Patel RV, Thaker VT, Patel VK. Antimicrobial activity of ginger and honey on isolates of extracted carious teeth during orthodontic treatment. Asian Pac J Trop Biomed 2011;1(1):5861.

[30] Weli TA, Mohammed AT. Effect of ginger extract on Mutans streptococci in comparison to chlorhexidine gluconate. J Baghdad Coll Dent 2013;25(2):179-184.

[31] Sudarshan R, Vijayabala GS. Role of ginger in medicine and dentistry: an interesting review article. Southeast Asian J Case Rep Rev 2012;1(3):66-72.

How to cite this article: Beyza Kiristioglu Z, Yanikoglu F, Alkan E, Tagtekin D, Gocmen GB, Ilgin C. The Effect of Dental Paste with Herbal Content on Remineralization and the Imaging with Fluorescent Technique in Teeth with White Spot Lesion. Clin Exp Health Sci 2021; 11: 348-353. DOI: 10.33808/clinexphealthsci.848455 